\title{
PERANCANGAN PERCOBAAN FAKTORIAL RAL UNTUK ANALISIS PENGARUH INTERAKSI UMUR BETON DAN PENAMBAHAN ABU SEKAM PADI TERHADAP KUAT TEKAN BETON
}

\author{
Y. Fitri' ${ }^{1}$, Fadjryani², dan Rais ${ }^{3}$ \\ 1Program Studi Matematika Jurusan Matematika FMIPA Universitas Tadulako \\ Jalan Soekarno-Hatta Km. 09 Tondo, Palu 94118, Indonesia. \\ 2,3Program Studi Statistik Jurusan Matematika FMIPA Universitas Tadulako \\ Jalan Soekarno-Hatta Km. 09 Tondo, Palu 94118, Indonesia. \\ 1Fyuhelni@yahoo.com, 2Fadjryani_mipauntad@yahoo.com, 3Rais76_untad@yahoo.co.id
}

\begin{abstract}
Concrete is a mixture of coarse aggregate and fine aggregate which consist of sand and gravel by adding cement adhesive and water. One of the concrete performances which usually overlooked is its comprehensive strength. Compressive strength of concrete is concrete's ability to receive a compressive force per unit area. Concrete strength is influenced by age and adhesives in the form of added material which has pozzolan characteristics and has very fine particles, one of which is rice husk ash. Rice husk ash is the result of burning husk or bran. In order to create good quality of compressive strength therefore a research was carried out on the effect of the amount of rice husk ash and concrete age as well as the interaction of a combination treatment of the compressive strength of concrete with a cube -shaped test specimens measuring $15 \times 15 \times 15 \mathrm{~cm}$. This experiment is a two- factor experiment and design environment used is a completely randomized design. This design is called a factorial design RAL. The first factor is the age of the concrete which consists of four levels, namely the age of 3 days, 7 days, 14 days and 21 days. The second factor is the rice husk ash, consisting of 3 levels of $0 \%, 10 \%$ and $20 \%$. The observed response is the compressive strength of concrete. Number of treatment combinations as much as 12. The experiment was repeated 3 times so that the unit experiment as much as 36 units. Each unit of the experiment was given in the form of an emphasis on the sample using the compressive strength of concrete machinery (unconfined compression). Based on Analysis of Variance, it is concluded that the age, the rice husk ash, interaction of age and rice husk ash significantly affect the strength of concrete as indicated by the acquisition of a p-value which is less than $5 \%$ significance level. HSD (Honest Significance Difference) obtained the best treatment combination occurs in the concrete age of 21 days with the addition of $10 \%$ rice husk ash in a total of $28,296 \mathrm{MPa}$. It can be said that the $10 \%$ addition of rice husk ash from the total amount of the cement in the concrete mixture is the best mixture and it creates high quality concretes.
\end{abstract}

Keywords $\quad$ : Compressive Strength of Concrete, Design Experiment, Factorial in RAL, Honest Significance Difference 


\section{ABSTRAK}

Beton adalah suatu campuran bahan-bahan agregat halus dan agregat kasar yaitu pasir, batu kerikil dengan menambahkan bahan perekat semen, dan air. Salah satu kinerja beton yang sering diperhatikan adalah kekuatan tekan. Kuat tekan beton merupakan kemampuan beton untuk menerima gaya tekan persatuan luas. Kekuatan beton dipengaruhi oleh umur dan perekat berupa bahan tambah yang bersifat pozzolan serta mempunyai partikel yang sangat halus salah satunya adalah abu sekam padi. Abu sekam padi merupakan hasil pembakaran sekam atau kulit padi. Dalam rangka menciptakan kuat tekan dengan mutu bagus dilakukan penelitian terhadap pengaruh jumlah abu sekam padi dan umur beton serta interaksi kombinasi perlakuan terhadap kuat tekan beton dengan benda uji berbentuk kubus berukuran 15×15×15 cm. Percobaan ini merupakan percobaan dua faktor dan menggunakan rancangan lingkungannya adalah rancangan acak lengkap. Rancangan semacam ini disebut rancangan Faktorial RAL. Faktor pertama adalah umur beton yang terdiri dari 4 (empat) taraf yaitu umur 3 hari, 7 hari, 14 hari dan 21 hari. Faktor kedua adalah abu sekam padi, terdiri dari 3 taraf yaitu 0\%, 10\% dan 20\%. Respon yang diamati adalah kuat tekan beton. Jumlah kombinasi perlakuan sebanyak 12. Percobaan tersebut diulang sebanyak 3 kali sehingga unit percobaan sebanyak 36 unit. Tiap unit percobaan diberi berupa penekanan terhadap sampel menggunakan mesin kuat tekan beton (Uncofined Compression). Dari tabel sidik ragam diperoleh kesimpulan bahwa umur, abu sekam padi, interaksi umur dan abu sekam padi berpengaruh signifikan terhadap kuat tekan beton yang ditunjukkan dengan perolehan nilai $p$ yang kurang dari taraf nyata $5 \%$. Berdasarkan hasil dari uji lanjut Beda Nyata Jujur diperoleh kombinasi perlakuan terbaik terjadi pada umur beton 21 hari dengan penambahan abu sekam padi 10\% dengan kuat tekan sebesar 28,296 Mpa.

\section{Kata Kunci $\quad$ : Faktorial RAL, Kuat Tekan Beton, Rancangan Percobaan, Uji Beda Nyata Jujur}

\section{PENDAHULUAN}

Beton adalah suatu campuran bahan-bahan agregat halus dan agregat kasar yaitu pasir, batu kerikil atau bahan semacam lainnya, dengan menambahkan bahan perekat semen, dan air sebagai bahan pembantu sampai menjadi satu kesatuan yang homogeny. Salah satu kinerja beton yang sering diperhatikan adalah kekuatan tekan. Kekuatan tekan adalah kemampuan beton untuk dapat menerima gaya per satuan luas (Mulyono., Tri, 2004). Menurut SNI 03-2847-2002 kuat tekan beton normal berkisar sekitar 17,5 Mpa. Secara umum kekuatan beton dipengaruhi oleh umur, perekat dan kerapatan beton, untuk memperoleh perekat dan kerapatan beton secara maksimal diperlukan bahan tambah yang bersifat pozzolan dan mempunyai partikel yang sangat halus (Falviana TL, 2011). Salah satunya adalah abu sekam padi. Pada penelitian ini akan dilakukan percobaan dengan melibatkan dua faktor untuk melihat pengaruh umur, abu sekam, interaksi umur beton dengan abu sekam padi terhadap kuat tekan beton serta berapa besar nilai perbedaan nyata rata-rata antar perlakuan dengan kondisi umur beton. Jumlah abu sekam padi yang dipercobaan dianggap memiliki kualitas seragam. Percobaan semacam ini disebut faktorial RAL (Fadjryani \& Ginanjar A, 2014). 


\section{METODE PENELITIAN}

\subsection{Metodologi}

Melakukan studi pustaka dengan mengumpulkan materi dari berbagai sumber seperti buku, jurnal dan internet. Tahap identifikasi meliputi penentuan tujuan penelitian, tinjauan pustaka, merancang percobaan faktoral RAL dan identifikasi data penelitian serta merumuskan masalah yang akan diteliti. Lokasi penelitian dan pengambilan data yang digunakan adalah Laboratorium Beton Jurusan Teknik Sipil Universitas Tadulako Palu sedangkan tempat analisa atau pengolahan data di Lab. Komputer Jurusan Matematika FMIPA UNTAD. Sumber data pada penelitian ini yaitu data primer yang diperoleh dari Laboratorium Beton Jurusan Teknik Sipil Universitas Tadulako Palu (Sulawesi Tengah). Jenis data dalam penelitian ini menggunakan data kuantitatif yaitu data berupa angka. Variabel penelitian dalam rancangan percobaan ini ada 2 yaitu variabel bebas dan variabel respon. Pada penelitian ini variabel bebas disebut dengan faktor, ada 2 faktor yang akan di uji yaitu umur $\left(x_{1}\right)$, dan jumlah abu sekam padi $\left(x_{2}\right)$ sedangkan pada variabel respon yaitu kuat tekan beton $\left(y_{1}\right)$.

\subsection{Rancangan Faktorial RAL}

Prinsip dasar dari rancangan percobaan yaitu pengacakan, pengulangan dan pengendalian lingkungan. Percobaan faktorial RAL dicirikan oleh perlakuan yang merupakan komposisi dan semua kemungkinan kombinasi dari taraf-taraf dua faktor atau lebih dengan unit percobaan yang digunakan relatif seragam (Mattjik AA \& Sumertajaya IM, 2000). Model linier aditif faktorial RAL adalah $Y_{i j k}=\mu+\alpha_{i}+\beta_{j}+(\alpha \beta)_{i j}+\varepsilon_{i j k}$ dimana :

$\mathrm{Y}_{\mathrm{ijk}} \quad=$ Nilai pengamatan faktor umur taraf ke-i, faktor abu sekam padi taraf ke-j dan ulangan ke-k

$\mu \quad=$ Pengaruh umum

$\mathrm{a}_{\mathrm{i}} \quad=$ Pengaruh utama faktor umur taraf ke-i, $\mathrm{i}=1,2,3,4$

$\beta_{\mathrm{j}} \quad=$ Pengaruh utama faktor abu sekam padi taraf ke-j, $\mathrm{j}=1,2,3$

$(\alpha \beta)_{i j}=$ Komponen interaksi dari faktor umur dan fakor abu sekam padi

$\varepsilon_{\mathrm{ijk}} \quad=$ Pengaruh acak yang menyebar normal $\left(0, \sigma^{2}\right)$

Berikut sumber-sumber keragaman faktorial Ral:

Tabel 1 : Sumber-Sumber Keragaman

\begin{tabular}{|l|l|c|c|c|c|}
\hline Sumber Keragaman & $\mathrm{db}$ & $\begin{array}{c}\text { Jumlah } \\
\text { Kuadrat }\end{array}$ & $\begin{array}{c}\text { Kuadrat } \\
\text { Tengah }\end{array}$ & F-hitung & F-tabel \\
\hline Faktor U & $\mathrm{u}-1$ & JKU & KTU & KTU/KTG $(\mathrm{u})$ & $\mathrm{F}_{(\mathrm{a}, \mathrm{db}-\mathrm{U}, \mathrm{db}-\mathrm{G}(\mathrm{a}))}$ \\
\hline
\end{tabular}




\begin{tabular}{|l|l|c|c|c|l|}
\hline Faktor A & $\mathrm{a}-1$ & JKA & KTA & KTA/KTG(a) & $F_{(a, \text { db-A, db-G(a)) }}$ \\
\hline Interaksi U*A & $(\mathrm{u}-1)(\mathrm{a}-1)$ & JKUA & KTUA & KTUA/KTG(a) & $\mathrm{F}_{(\mathrm{a}, \mathrm{db}-\mathrm{AB}, \mathrm{db}-\mathrm{G}(\mathrm{a}))}$ \\
\hline Galat U & $\mathrm{ua}(\mathrm{r}-1)$ & JKG $(\mathrm{u})$ & $\mathrm{KTG}(\mathrm{u})$ & & \\
\hline Galat A & $\mathrm{ua}(\mathrm{r}-1)$ & JKG $(\mathrm{a})$ & $\mathrm{KTG}(\mathrm{a})$ & & \\
\hline Galat U*A & $\mathrm{ua}(\mathrm{r}-1)$ & JKG & KTG & & \\
\hline Total & uar-1 & JKT & & & \\
\hline
\end{tabular}

Dengan langkah-langkah perhitungan jumlah kuadrat sebagai berikut:

1. $\quad F K=$ Faktor Koreksi

$F K=\frac{Y^{2}}{a b r}$

2. $\mathrm{JKT}=$ Jumlah Kuadrat Total

$J K T=\sum_{i=1}^{u} \sum_{j=1}^{a} \sum_{k=1}^{r}\left(Y_{I J K}-\bar{Y}\right) \sum \sum \sum Y_{I J K}^{2}-F K$

3. $\mathrm{JKU}=$ Jumlah Kuadrat Faktor Umur

$J K U=\sum_{i=1}^{u} \sum_{j=1}^{a} \sum_{k=1}^{r}(Y i-\bar{Y})^{2}=\sum \frac{Y_{i}^{2}}{b r}-F K$.

4. $\quad \mathrm{JKA}=$ Jumlah Kuadrat Faktor Abu Sekam Padi

$J K A=\sum_{i=1}^{u} \sum_{j=1}^{a} \sum_{k=1}^{r}(Y j-\bar{Y})^{2}=\sum \frac{Y_{j}^{2}}{b r}-F K$

5. JKUA = Jumlah Kuadrat Interaksi Faktor $U$ dengan Faktor $A$

$J K U A=\sum_{i=1}^{u} \sum_{j=1}^{a} \sum_{k=1}^{r}\left(\bar{Y}_{i j \ldots}-\bar{Y}_{i \ldots .}-\bar{Y}_{j \ldots}+\bar{Y}_{\ldots . .}\right)^{2}=\sum_{i=1}^{u} \sum_{j=1}^{a}\left(\bar{Y}_{i j \ldots}-\bar{Y}_{\ldots}\right)^{2}-J K U-J K U$

$J K U A=J K P-J K A-J K B$

6. $\quad \mathrm{JKG}=$ Jumlah Kuadrat Galat

$J K G=J K T-J K P$

\subsection{Perbandingan Nilai Tengah Perlakuan (Uji BNJ)}

Uji ANOVA hanya memberikan indikasi tentang ada tidaknya beda antar rata-rata dari keseluruhan perlakuan, namun belum memberikan informasi tentang ada tidaknya pengaruh masing-masing tingkat faktor (perlakuan) terhadap respon (kuat tekan beton). Salah satu prosedur uji yang paling sederhana untuk menjawab pertanyaan tersebut adalah dengan melakukan uji lanjut (Post hoc test), dari uji lanjut ini dapat ditentukan perlakuan atau kisaran tingkat faktor yang terbaik. Jadi, sebenarnya sasaran percobaan dituntaskan pada taraf ini. Namun, uji lanjut dapat digunakan jika pada perhitungan faktorial RAL perlakuan memberikan pengaruh terhadap respon.

Ada berbagai macam jenis uji lanjut, namun pada penelitian ini uji lanjut yang digunakan yaitu uji BNJ (Beda Nyata Jujur). Uji beda nyata jujur (BNJ) sering juga disebut uji Turkey atau Honestly Significant Difference (HSD). Prosedur pengujian BNJ menggunakan lebih dari tiga pembanding dengan tujuan menguji seluruh pasangan rata-rata perlakuan tanpa rencana. Pada penelitian ini terdapat 12 kombinasi perlakuan sebagai pembanding. 
Apabila setiap perlakuan mempunyai ulangan yang sama yaitu $r$, maka formula untuk perhitungan nilai BNJ pada taraf nyata $\alpha$ adalah:

$B N J_{\alpha}=q_{(p, \text { db galat }, \alpha)} x \sqrt{\frac{K T G}{r}}$

Nilai $q_{\alpha}$ dilihat pada tabel BNJ (tukey) dimana $\mathrm{p}$ adalah jumlah perlakuan dan db galat adalah derajat bebas galat, dengan $\alpha$ sebesar $5 \%$.

\subsection{Pembuatan Benda Uji dan Pengujian Kuat Tekan Beton}

1. Mempersiapkan benda uji. Benda uji yang dibutuhkan pada penelitian ini yaitu 36 benda uji. 12 benda uji untuk beton normal $+0 \%$ abu sekam, 12 benda uji untuk beton normal $+10 \%$ abu sekam, 12 benda uji untuk beton normal $+20 \%$ abu sekam. Alat dan bahan yang digunakan yaitu alat uji kuat tekan Uncofined Compression, cetakan kubus berukuran $15 \times 15 \times 15 \mathrm{~cm}$, semen $54 \mathrm{~kg}$, pasir $108 \mathrm{~kg}$, kerikil $162 \mathrm{~kg}$, abu sekam padi sejumlah $0 \%, 10 \%, 20 \%$ dari jumlah semen beton normal, mesin pengaduk beton, tongkat pemadat dengan diameter $16 \mathrm{~mm}$ panjang $60 \mathrm{~cm}$ ujung bulat yang terbuat dari baja tahan kerat, timbangan ketelitian $0,3 \%$ dari berat uji sampel, satu set alat pelapis, satu set alat pemeriksaan berat isi beton, satu set alat pemeriksaan slump, dan alat tambahan ember, sekop, sendok, perata, talam.

2. Pembuatan benda uji dengan cara pengadukan, menentukan nilai slump, membuat benda uji dengan cetakan kubus $15 \times 15 \times 15 \mathrm{~cm}$.

3. Pengujian kuat tekan. membersihkan benda uji dari kotoran yang menempel dengan kain lembab, selanjutnya benda uji ditimbang beratnya dan siap diperiksa, benda uji diletakan pada mesin kuat tekan beton (Uncofined Compression) secara simetris dan mesin penekan dijalankan dengan menambahkan beban, menambahkan beban sampai benda uji hancur dan mencatat beban maksimum yang diberikan monitor selama percobaan benda uji dilakukan.

\subsection{Teknik Analisa Data}

Teknik yang dilakukan oleh peneliti dalam mengkaji data-data yang telah diperoleh dari sumbernya adalah dengan menggunakan faktorial RAL dengan dibantu aplikasi program MINITAB. Teknik analisa data yang digunakan pada penelitian ini diawal dengan mendeskripsikan data respon setiap kombinasi perlakuan, mengacak dan mendesai data, mengolah data dengan minitab ( uji Asumsi dan ANOVA), menganalisis ANOVA, membuat keputusan, melanjutkan dengan uji lanjut $\mathrm{BNJ}$ dan membuat kesimpulan. 


\section{HASIL DAN PEMBAHASAN}

\subsection{Deskripsi Data dan Rancangan}

Pengujian yang dilakukan pada percobaan ini bertujuan untuk melihat pengaruh faktor umur $\left(x_{1}\right)$ dan abu sekam padi $\left(x_{2}\right)$ terhadap kuat tekan beton (respon). Data yang digunakan adalah data hasil percobaan faktorial dengan 2 faktor yaitu umur beton $\left(x_{1}\right)$ dan jumlah abu sekam padi $\left(x_{2}\right)$. Dimana setiap faktor memiliki taraf yang berbeda-beda yaitu umur beton $\left(x_{1}\right)$ memiliki 4 taraf yang terdiri dari 3 hari, 7 hari, 14 hari dan 21 hari dan jumlah abu sekam padi $\left(x_{2}\right)$ memiliki 3 taraf yaitu $0 \%, 10 \%$ dan 20\% dari ukuran semen normal, dengan kombinasi perlakuan sebanyak 12 perlakuan yang diulang sebanyak 3 kali. Dengan demikian, terdapat 36 unit percobaan.

Tabel 2 : Tabulasi Data Percobaan

\begin{tabular}{|c|c|c|c|c|c|}
\hline \multirow[t]{2}{*}{ Umur Beton } & \multirow{2}{*}{ Ulangan } & \multicolumn{3}{|c|}{ Abu Sekam ( \% ) } & \multirow{2}{*}{ Total $\left(Y_{1}\right)$} \\
\hline & & 0 & 10 & 20 & \\
\hline \multirow{4}{*}{3 Hari } & 1 & 14.199 & 16.203 & 15.549 & \multirow{4}{*}{142.47} \\
\hline & 2 & 15.244 & 16.595 & 16.333 & \\
\hline & 3 & 16.290 & 15.985 & 16.072 & \\
\hline & Total & 45.733 & 48.783 & 47.954 & \\
\hline \multirow{4}{*}{7 Hari } & 1 & 17.858 & 18.642 & 17.901 & \multirow{4}{*}{169.089} \\
\hline & 2 & 19.077 & 19.128 & 18.729 & \\
\hline & 3 & 18.555 & 20.166 & 19.933 & \\
\hline & Total & 55.490 & 57.936 & 55.663 & \\
\hline \multirow{4}{*}{14 Hari } & 1 & 21.865 & 23.476 & 22.213 & \multirow{4}{*}{206.888} \\
\hline & 2 & 22.692 & 23.259 & 23.085 & \\
\hline & 3 & 23.389 & 23.912 & 22.997 & \\
\hline & Total & 67.946 & 70.647 & 68.295 & \\
\hline \multirow{4}{*}{21 Hari } & 1 & 26.438 & 27.309 & 26.656 & \multirow{4}{*}{247.481} \\
\hline & 2 & 27.136 & 28.877 & 27.222 & \\
\hline & 3 & 27.440 & 28.703 & 27.701 & \\
\hline & Total & 81.013 & 84.889 & 81.579 & \\
\hline \multicolumn{2}{|c|}{ Total $\left(Y_{J}\right)$} & 250.182 & 262.255 & 253.491 & 765.928 \\
\hline
\end{tabular}

Dari tabel diatas pemberian tambahan abu sekam padi, kuat tekannya lebih tinggi dari pada beton tanpa abu sekam padi. Sedangkan, semakin bertambah usia beton kuat tekan betonpun semakin meningkat. Sehingga dapat dikatakan umur beton dan jumlah abu sekam padi memberikan pengaruh terhadap kuat tekan beton. Berikut grafik hasil pengujian rata-rata kuat tekan beton akibat pengaruh faktor umur dan faktor abu sekam padi. 


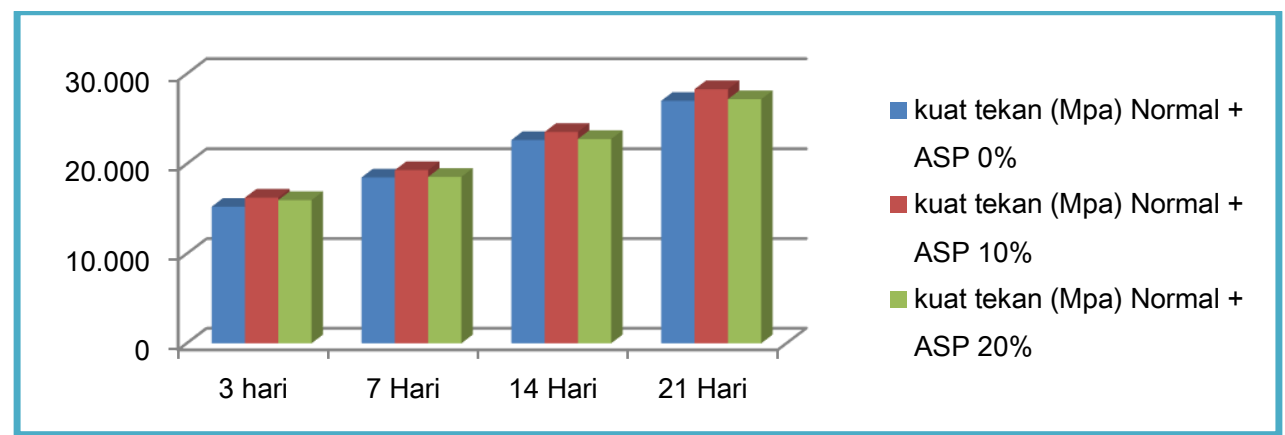

Gambar 1 : Grafik rata-rata kuat tekan beton akibat pengaruh faktor umur dan factor abu sekam.

Dari gambar 1 dapat dilihat adanya perbedaan kuat tekan antara beton tanpa abu sekam padi dengan beton yang diberi tambahan abu sekam padi sejumlah $10 \%$ dan $20 \%$. Beton tampa abu sekam padi memeiliki kuat tekan beton tertinggi sebesar 27,004 MPa pada saat beton berumur 21 hari, beton dengan tambahan abu sekam padi $10 \%$ dari jumlah semen memiliki kekuatan tertinggi disaat berumur 21 hari yaitu 28, $296 \mathrm{MPa}$ dan beton dengan tambahan abu sekam padi sejumlah $20 \%$ dari jumlah semen memiliki kuat tekan tertinggi 27,193 MPa pada saat beton berumur 21 hari.

\section{2. $\quad$ Uji Asumsi Plot Normal dan Plot Sisaan}

Sebelum melakukan analisis dengan menggunakan metode permukaan respon, terlebih dahulu perlu dilakukan uji asumsi terhadap data penelitian. Uji asumsi yang dilakukan dalam penelitian ini meliputi uji normalitas dan uji kehomogenan.
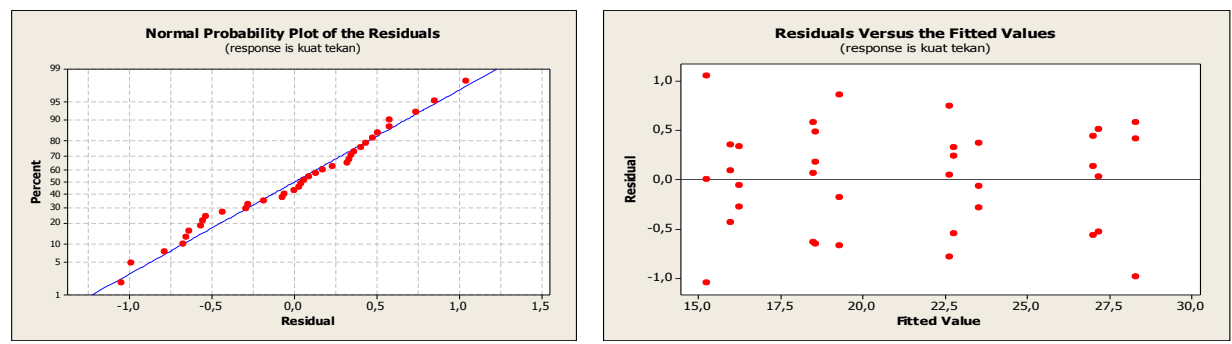

Gambar 2 : Plot kenormalan dan plot sisaan respon rata-rata kuat tekan beton.

Diagnosis melalui plot kenormalan dan plot sisaan gambar 4.3 untuk data respon ratarata kuat tekan beton, dari plot kenormalan titik-titik membentuk pola mendekati garis lurus. Ini menunjukan bahwa data respon rata-rata kuat tekan beton yang diperoleh telah berdistribusi normal. Oleh sebab itu dapat dikatakan bahwa asumsi kenormalan data 
terpenuhi. Sedangkan plot sisaan kehomogenan ragam terlihat titik-titik disekitar garis 0 atau tidak terdapat nilai sisaan yang terlalu memisah jauh dari nilai sisaan lainnya. Hal ini mengindikasikan tidak adanya gejala kehetrogenan ragam yang parah, dengan kata lain asumsi kebebasan sisaan dan kehomogenan ragam terpenuhi.

\subsection{Analisis Faktorial RAL}

Penguraian keragaman total akan dilakukan untuk faktor Umur (U) dan Faktor Abu sekam padi $(A)$ dengan rancangan lingkungan RAL. Sebagai kasus faktor umur $(U)$ terdiri dari 4 taraf yaitu 3 hari, 7 hari, 14 hari, 21 hari dan faktor abu sekam padi (A) terdiri dari 3 taraf yaitu $0 \%, 10 \%, 20 \%$ dan setiap perlakuan diulang sebanyak 3 kali, dengan a sebesar $5 \%$, berikut sumber-sumber keragaman faktorial:

Tabel 3 : Analisis Sidik Ragam

\begin{tabular}{|l|c|c|c|c|c|}
\hline \multicolumn{1}{|c|}{ Sumber Keragaman } & $\mathrm{db}$ & Jumlah Kuadrat & Kuadrat Tengah & $F_{\text {hitung }}$ & $F_{\text {tabel }}$ \\
\hline Faktor Umur & 3 & 697,428 & 232,476 & 572,77 & 3,01 \\
\hline Faktor Abu sekam & 2 & 6,487 & 3,243 & 7,99 & 3,40 \\
\hline Interaksi Umur*Abu Sekam & 6 & 20,775 & 3,463 & 8,53 & 2,51 \\
\hline Galat & 24 & 9,741 & 0,406 & & \\
\hline Total & 35 & 714,431 & & & \\
\hline
\end{tabular}

Interpretasi Tabel Sidik Ragam

a. Variabel Umur beton (hari).

$F_{\text {hitung }}>F_{\text {tabel }(\alpha, d b-U, d b-G(a))}=572,77>3,01$ maka hipotesis nol ditolak. Hal ini berarti umur beton berpengaruh terhadap kuat tekan beton dengan $\alpha=0,05$.

b. Variabel Jumlah abu sekam padi (\%).

$F_{\text {hitung }}>F_{\text {tabel }(a, \text { db-A, db-G(a)) }}=7,99>3,40$ maka hipotesis nol ditolak. Hal ini berarti jumlah abu sekam padi berpengaruh terhadap kuat tekan beton dengan $\alpha=0,05$.

c. Variabel kombinasi perlakuan interaksi antara umur beton dan jumlah abu sekam padi.

$F_{\text {hitung }}>F_{\text {tabel }}(a, d b-U A, d b-G(a))=8,53>2,51$ maka hipotesis nol ditolak. Hal ini berarti interaksi umur beton dan jumlah abu sekam padi berpengaruh terhadap kuat tekan beton dengan $\alpha=0,05$.

\subsection{Uji Lanjut Beda Nyata Jujur}

Pada uji ANOVA menunjukkan adanya pengaruh perlakuan yang nyata secara statistik, maka dilakukan uji lanjut BNJ untuk mengetahui ada tidaknya pengaruh masing-masing tingkat faktor terhadap kuat tekan beton. Berikut langkah-langkah uji BNJ : 
a. Menentukan Nilai kritis

$B N J_{\alpha}=q_{(p, \text { db galat }, \alpha)} x \sqrt{\frac{K T G}{r}}=q_{12 ; 24,0,05} \sqrt{\frac{0,426}{3}}=5,10 \sqrt{\frac{0,426}{3}}=1,922$

b. Menyusun dan mengurutkan nilai rata-rata perlakuan dari terendah ketertinggi.

c. Selanjutnya adalah menentukan huruf pada nilai rata-rata tersebut dengan cara menjumlahkan nilai kritis $\mathrm{BNJ} 5 \%$. Berikut tabel perbandingan rata-rata perlakuan setelah diberi huruf.

Tabel 4 : Perbandingan rata-rata perlakuan setelah diberi huruf

\begin{tabular}{|l|l|}
\hline \multicolumn{1}{|c|}{ Perlakuan } & \multicolumn{1}{c|}{ Rata-Rata } \\
\hline 3 hari , 0\% (A) & $15,244 \mathrm{a}$ \\
\hline 3 hari , 20\% (B) & $15,986 \mathrm{ab}$ \\
\hline 3 hari , 10\% (C) & $16,261 \mathrm{abc}$ \\
\hline 7 hari , 0\% (D) & $18,496 \mathrm{~d}$ \\
\hline 7 hari , 20\% (E) & $18,555 \mathrm{de}$ \\
\hline 7 hari , 10\% (F) & $19,312 \mathrm{def}$ \\
\hline 14 hari , 0\% (G) & $22,649 \mathrm{~g}$ \\
\hline 14 hari , 20\% (H) & $22,769 \mathrm{gh}$ \\
\hline 14 hari , 10\% (I) & $23,549 \mathrm{ghi}$ \\
\hline 21 hari , 0\% (J) & $27,004 \mathrm{j}$ \\
\hline 21 hari , 20\% (K) & $27,193 \mathrm{jk}$ \\
\hline 21 hari , 10\% (L) & $28,296 \mathrm{jkl}$ \\
\hline
\end{tabular}

Dari tabel terlihat rata-rata tertinggi adalah rata-rata perlakuan $L$ yaitu 28,296 diikuti oleh huruf $\mathrm{I}$ itu sendiri. Jadi dapat disimpulkan perlakuan $\mathrm{L}$ adalah perlakuan yang terbaik, artinya kombinasi perlakuan terbaik terjadi pada umur beton 21 hari dengan penambahan abu sekam padi 10\% dengan kuat tekan sebesar 28,296 Mpa.

\section{KESIMPULAN}

Berdasarkan hasil penelitian dengan rancanagn faktorial RAL yang telah dilakukan, maka dapat disimpulkan bahwa :

1. Umur beton memberikan pengaruh terhadap kuat tekan beton karena semakin bertambah umur beton kadar air yang terdapat pada beton semakin berkurang sehingga kekuatan beton pun meningkat.

2. Jumlah abu sekam padi memberikan pengaruh terhadap kuat tekan beton. Penggunaan abu sekam padi dengan kombinasi campuran yang sesuai pada semen yaitu $10 \%$ dari jumlah semen menghasilkan kuat tekan yang lebih baik sedangkan sedangkan penggunaan abu sekam padi lebih dari $10 \%$ akan menghasilkan beton yang mengandung kadar air terlalu banyak. 
3. Kombinasi perlakuan antara umur beton dan jumlah abu sekam padi memberikan pengaruh terhadap kekuatan beton.

4. Berdasarkan hasil uji lanjut BNJ pada taraf $5 \%$ diperoleh hasil kombinasi perlakuan terbaik terjadi pada umur beton 21 hari dengan penambahan abu sekam padi $10 \%$ dengan kuat tekan sebesar 28,296 Mpa.

\section{DAFTAR PUSTAKA}

[1]. Fadjriyani dan Ginanjar A. 2014. Rancagan Percobaan Pengamatan Berulang Untuk Analisis Pengaruh Interaksi Cahaya dan Media Tanam Terhadap Pertumbuhan dan Perkembangan Perkecambahan Kacang Hijau. Palu.

[2]. Falviana TL. 2011. Pengaruh Abu Terbang dan Superpla Sticizer Terhadap Kuat Tekan Beton. Jurnal Teknika ,Vol XXXII, No 1. Palembang. Diakses pada tanggal 12 Januari 2013.

[3]. Kasih, R.Y.,Zuki, Z., dan Yusuf, Y. 2012. Pengaruh Penambahan Abu sekam Padi Terhadap Kuat Tekan Montar PCC Dengan Perendaman Dalam Asam Sulfat dan Analisi Larutan Rendaman Mortar. FMIPA Unand Padang. Jurnal Kimia Vol. 1 No. 1. Diakses pada tanggal 28 November 2014.

[4]. Mattjik AA, Sumertajaya IM. 2002. Perancangan Percobaan. Jilid I. Bogor : IPB Press.

[5]. Mulyono, Tri. 2004. Teknologi Beton. Penerbit Andi. Jakarta. 